\title{
Reseña de la evolución de las Relaciones Internacionales en América Latina ${ }^{1}$ Review of the evolution of International Relations in Latin-America
}

Recibido: 6 de agosto de 2015

Evaluado: 9 de septiembre de 2015 Aceptado: 23 de septiembre de 2015

\author{
Gustavo Londoño Ossa (Colombia) \\ Máster en Relaciones Internacionales \\ Gustavo.londono@esumer.edu.co
}

Diego Montoya Uribe (Colombia)

Magíster en Comercio y Relaciones internacionales

Diego.montoya@esumer.edu.co

Carlos González Parias (Colombia)

Magíster en Gobierno

Carlos.gonzalez88@esumer.edu.co

\section{Resumen}

A través de un recorrido histórico, se evidencia que las Relaciones Internacionales de América Latina están marcadas por necesidades económicas y, en gran medida, por la reacción ante las coyunturas internacionales propias de cada época. Siendo en buena medida la región un jugador poco activo y con poca capacidad de autodeterminación en materia internacional.

Aferradas a esas necesidades, desde la época de la colonia buscó apoyo para sus procesos de emancipación y prácticamente a lo largo de todo el siglo XX ha sostenido su dependencia con los Estados Unidos de América, a pesar de las manifestaciones en contra de estas relaciones, bien a causa de movimientos de ideología comunista, bien por actos de

\begin{abstract}
By means of a historical overview, it is possible to evidence that America Latina's international relations are set by economic needs and, to a great extent, by the reaction towards the international circumstances of each era. A less active player that has little selfdetermination capacity at international level is "region."

Latin America, since the colony, has looked for support for its emancipation process and throughout the XX century has depended on the United States even against manifestations against this relationship (due to communist movements, rebellion from certain Latin American countries, or to the alternative offered through integration processes within the so-called open regionalism.) However, the autonomy ideas of the region could be tracked from the Boli-
\end{abstract}

1 Este texto presenta los resultados de la investigación Integración y Regionalismo Abierto, realizada en el año 2014 por el Grupo de Investigación de Estudios Internacionales de la Institución Universitaria Esumer. 
rebeldía de algunos países latinoamericanos o bien por la alternativa que le ha sido ofrecida mediante procesos de integración en el llamado regionalismo abierto. No obstante, las ideas de autonomía en la región se pueden rastrear desde el pensamiento bolivariano, pero desarrolladas como un cuerpo coherente y disciplinar de las Relaciones Internacionales desde los años 70 del siglo XX.

Por otra parte, otro centro de referencia de la evolución de las Relaciones Internacionales, en buena parte de América Latina, ha sido las relaciones con la ex metrópoli. Las relaciones con España han variado según el transcurrir histórico y la posición en que aquella haya estado frente a los países latinoamericanos, pero ciertamente no se puede negar los lazos de lengua, cultura y sociedad que atan a unos y otros.

Palabras clave: Acuerdos de Integración, Bipolar, Guerras Mundiales, Procesos de Integración, Relaciones Internacionales. varian thinking and their development was based on the coherent and disciplinary body of the 70 s during the XX century.

On the other hand, another reference point of the evolution of these international relations in Latin America is the relationships with the ex-metropolis. Relationships with Spain have changed according to the time in history and its position regarding Latin American countries. It cannot be possible to deny the ties that exist between them (language, culture, and society.)

Key Words: Integration Agreements, bipolar, world wars, integration processes, international relations. 


\section{Introducción}

Desde un enfoque clásico de las teorías de las Relaciones Internacionales, los territorios latinoamericanos ingresan como jugadores y actores del sistema internacional, al momento de lograr su independencia frente al imperio colonizador respectivo e interactuar, como un igual jurídicamente, haciendo uso de su soberanía, frente a las demás unidades estatales del sistema. No obstante, América Latina, por diferentes factores como la debilidad institucionalidad estatal, la carencia de un proyecto nacional coherente y de largo plazo, las élites políticas locales, la tendencia al caudillismo y el personalismo político, la infructuosa búsqueda de una industrialización plena entre otros factores, hicieron de esta región un "jugador objeto" y no un "jugador actor" en las diferentes dinámicas de la política internacional. Es decir, en objeto de los intereses nacionales de las diferentes potencias durante el siglo XIX y XX, siguiendo el pensamiento realista de las Relaciones Internacionales.

En este orden de ideas, con el presente artículo se pretende guiar al lector por el trasegar del comportamiento de las Relaciones Internacionales de los países latinoamericanos, partiendo de unos antecedentes o sucesos previos a la obtención de la independencia, pasando por las principales coyunturas del siglo XX hasta un breve bosquejo de las dinámicas integracionistas en el actual siglo.

Se parte, por un lado, de la hipótesis que el marco histórico incide directamente en las relaciones y de acuerdo con el momento en que se encuentre, las naciones de América Latina han cambiado de posición, lo que evidencia, con algunas excepciones, que históricamente las políticas exteriores de los países de América Latina han sido reactivas frente a los estímulos y realidades particulares del sistema internacional. Por otra parte, lo que se hace muy claro, es que el factor económico ha primado cuando de Relaciones Internacionales se trata, y si bien hoy se ha ingresado a una era de procesos de integración que aglutinan otros factores, los económicos siguen siendo prioritarios. Como marco teórico de análisis se toma los aportes a la autonomía en Relaciones Internacionales, desarrollados principalmente en Suramérica.

De este modo, el artículo se estructura así: una primera parte en donde se explicita las bases teóricas y conceptuales a emplear. Una segunda parte en donde se describe los antecedentes y sucesos precursores a las Relaciones Internacionales de Latinoamérica en sentido estricto. La tercera parte corresponde a la identificación de diferentes procesos experimentados y las décadas posteriores a la consolidación de la independencia y de cómo la importancia geopolítica y la debilidad de las repúblicas las dejan a merced de intereses y disputas de jugadores geopolíticos como los Estados Unidos y las potencias europeas. Finalmente, una cuarte parte en donde se diserta acerca de los procesos de integración en América Latina, como eje dinamizador de estas relaciones.

\section{Metodología}

Para la realización del presente artículo, se recurre al método descriptivo, toda vez que mediante un trabajo de consulta que permitió construir un estado de arte abundante sobre el tema propuesto, se realiza una descripción histórica del proceso de Relaciones Internacionales en América Latina, sin que ello excluya, por parte de los autores, la utilización del análisis para que, junto con la casuística, ejemplarice por momentos un contexto histórico y evitar así que el artículo no termine siendo una mera cronología de hechos. 


\section{Referente Teórico}

Como parte del análisis se toma como categoría central el pensamiento autonómico latinoamericano desde la disciplina de las Relaciones Internacionales, especialmente los desarrollos realizados por Helio Jaguaribe y Juan Carlos Puig. Si bien el pensamiento autonómico de manera disciplinar y coherente surge avanzada la segunda mitad del siglo XX, tal y como lo detalla de muy buena forma José Briceño, en el artículo titulado: Autonomía: genealogía y desarrollo de un concepto: su relación con el Regionalismo (2014), en donde establece la diferencia entre el saber autonómico y propuestas autonómicas académicas enmarcadas en una campo de estudio específico como son las Relaciones Internacionales.

Por saber autonómico se entiende una serie de formaciones discusivas e iniciativas, surgidas en América Latina inmediatamente después de obtenida las independencias en el siglo XIX, hasta inicios del XX, las cuales tenían como propósito complementar la soberanía externa, con una ampliación de su capacidad de tomar decisiones en el sistema internacional (Briceño, 2014), formaciones discursivas e iniciativas tales como la Carta de Jamaica, el Congreso de Panamá de 1826, la idea de un Congreso Americano impulsado por Juan Bautista Alberdi en 1844, la creación de la sociedad para Unión Americana en 1862.

Propuesta autonomista se refiere a aquellos trabajos, aportes y desarrollos surgidos entre las décadas 70 y 80 del siglo XX, principalmente en el cono sur. Tales desarrollos constituyen uno de los más importantes aportes de la región al pensamiento en las Relaciones Internacionales como disciplina académica. Como propuesta, la Autonomía aparece inicialmente desde la perspectiva de los ejes que vinculan desarrollo-dependencia con la subordinación política-independencia (Piñero, 2012)

Siendo los primeros desarrolladores, como ya ha sido señalado, Juan Carlos Puig, desde la Argentina, y Helio Jaguaribe, desde Brasil. Tal pensamiento surge precisamente en un contexto regional y mundial particular. En un contexto en el que la región, en el marco de la guerra fría, vivía el punto más álgido de la doctrina Monroe y vio altamente recortados sus márgenes de autonomía y actuación independiente a nivel exterior. No obstante, tal categoría de análisis es susceptible de aplicación a periodos históricos anteriores al bipolar.

Juan Carlos Puig entenderá a la autonomía como la máxima capacidad de decisión propia que se puede lograr, teniendo en cuenta los condicionamientos objetivos del mundo real (Puig, 1980). Como señala Gladys Lechini (2014), citando a Puig: Autonomía es disponer de un mayor margen de maniobra para adoptar las decisiones que afecten directamente sus objetivos, y se define como la "(...) capacidad de una nación para optar, decidir y obrar por sí misma”. Tales condicionamientos del mundo real, en el contexto de los desarrollos de Puig, eran básicamente los impuestos en el marco de un sistema bipolar.

Por lo tanto, continuando con los aportes de Lechini en su análisis de Puig, se considera que ser autónomo, a grandes rasgos, requiere que el Estado nación cuente con un modelo de desarrollo económico propio; con un sistema político inclusivo y de mayorías; y que participe en el sistema internacional en función de sus propios intereses (Lechini, 2014).

Por su parte, Jaguaribe reconoce la existencia de una estratificación internacional, establecida con base en las capacidades materiales y el nivel de maniobra y autodeterminación en el sistema internacional. 
Explica este autor brasilero que el rol que ocupen en dicha estratificación los Estados determina el grado de autonomía de estos. En este sentido, tal estratificación, para Jaguaribe, se clasifica en cuatro niveles:

En primer lugar, los países ubicados en el nivel de primacía general poseen atributos como la inexpugnabilidad de su territorio nacional (principalmente por contar con capacidad disuasiva nuclear) y la capacidad de ejercer una supremacía mundial considerable. Un segundo lugar, los Estados en un nivel de primacía regional pueden garantizar la inviolabilidad de su territorio y ejercer hegemonía sobre unas áreas y actuar preponderantemente en otras. En tercer lugar, las naciones en el nivel de la autonomía, quienes a pesar de no poder garantizar la inexpugnabilidad de su territorio nacional, tienen los recursos para imponer severas penalidades -materiales y morales- a eventuales agresores. Asimismo, los países que cuentan con el atributo de la autonomía se caracterizan por tener un holgado margen de autodeterminación en sus asuntos domésticos y una capacidad de actuación internacional independiente [...] En cuarto y último lugar, en el nivel de dependencia se ubican la mayoría de los países. La actuación de éstos se encuentra condicionada por factores y decisiones externas (tomadas por Estados en los tres niveles anteriores), a pesar de contar nominalmente con el estatus de naciones soberanas. (Tokatlian \& Carvajal, 1995)

Figura No. 1: Estratificación Internacional según Modelo de Helio

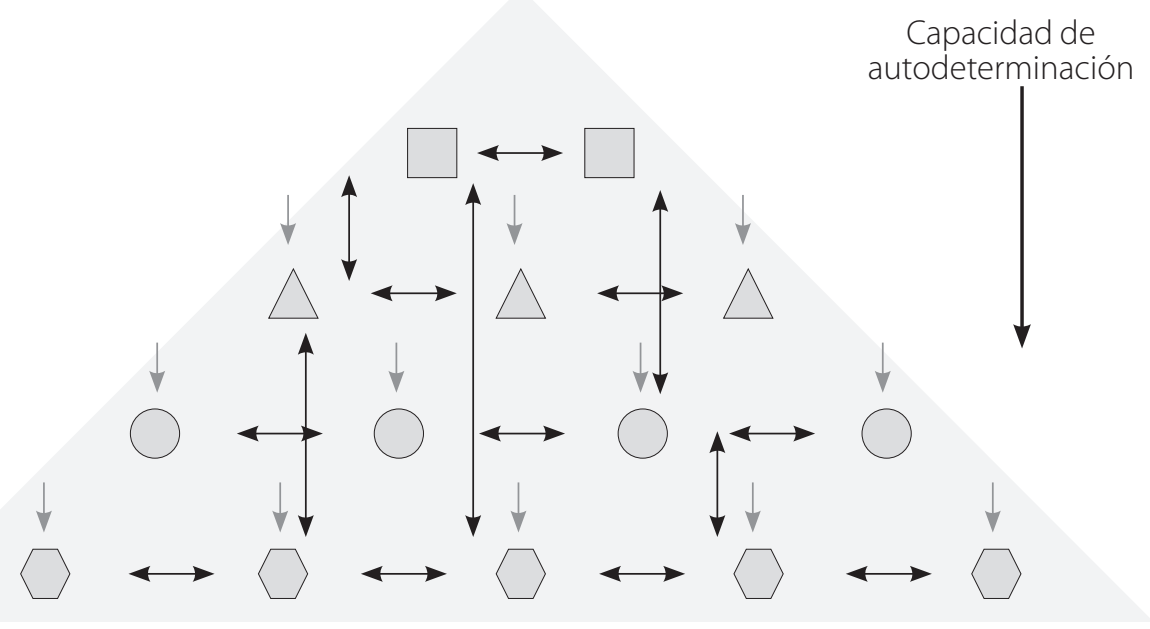

\begin{tabular}{|c|c|c|c|c|c|}
\hline$\square$ & $\triangle$ & $\bigcirc$ & $\square$ & $\downarrow$ & $\longleftrightarrow$ \\
\hline $\begin{array}{c}\text { Primacía } \\
\text { General }\end{array}$ & $\begin{array}{c}\text { Primacía } \\
\text { Regional }\end{array}$ & $\begin{array}{c}\text { Nivel de } \\
\text { autonomía }\end{array}$ & $\begin{array}{c}\text { Nivel de } \\
\text { dependencia }\end{array}$ & Condicionamientos & Interacciones \\
\hline
\end{tabular}

Fuente: Elaboración propia con base en Tokatlian \& Carvajal (1995) 
No obstante, en este punto se debe señalar el importante énfasis que Jaguaribe coloca a las élites del país para la consecución de un proyecto autonomista, las cuales se pueden convertir en un elemento que obstaculiza o que lidera y promueve tal proyecto.

Para Jaguaribe la condición de dependencia - autonomía estaría altamente condicionada por las élites, y de allí se deriva que a través de la funcionalidad de las mismas al proyecto nacional es que un Estado puede alcanzar el status de autónomo. De esta forma, ninguna estrategia autonómica puede realizarse si no se parte del apoyo de las élites, las cuales deben estar comprometidas con dicho objetivo y asumir como propia la construcción de las prácticas autonomistas. (Lechini, 2014)

No obstante, en esta reflexión, se prima la importancia de los condicionamientos externos como factores decisivos, sin desconocer los demás, en la consecución de un proyecto autonomista. También, se emplea el sistema de estratificación estatal de Jaguaribe, al considerarlo como aquel que simplifica de buena forma la posición y el escaso margen de autonomía que caracteriza a buena parte de la región durante los contextos históricos que aquí se repasan.

Bajo las concepciones anteriores, en esta reflexión se sostiene que históricamente la región latinoamericana ha carecido de mayores márgenes de autonomía como para estructurar a nivel interno y nacional proyectos coherentes, propios, autodeterminantes y lograr relacionarse en el contexto internacional en pro de la consecución de intereses nacionales. Sin olvidar, también, algunos gobiernos en la región que han propendido por ampliar los márgenes de autonomía, especialmente Brasil y Argentina.

\section{Siglo XIX; influencias y antecedentes}

\section{Precursores}

Entre los Siglos XV y XVII, América es definitivamente una región colonial, sumisa y sin evidencias de expresiones de autonomía. La dependencia frente a las monarquías inglesas, españolas, francesas, portuguesas y holandesas principalmente, nos ubican en territorios que se comportan desde lo social, económico, cultural y político de conformidad con el mandato de cada reino. No obstante, desde 1776, la independencia de los Estados Unidos, y en 1789, la Revolución Francesa, propagan una serie de ideas que de a poco irán consolidando los movimientos independentistas de América Latina, en donde los territorios optan por asumir modelos de forma de organización sociopolítica heredados de Europa y en menor medida de los Estados Unidos, toman como base el modelo Westfaliano cuyos desarrollos principales fueron: la noción y práctica de la soberanía, la aparición de un control centralizado de las instituciones y surgimiento del sistema capitalista (Mingst, 2007, p. 61), modelo que se consolida con los aportes de las revoluciones anteriormente mencionadas.

En medio de estos iconos, curiosamente se encuentran alianzas en Europa que generan un marco de Relaciones Internacionales directamente involucradas con aquellos: alianza Inglaterra y Portugal, alianza Espańa con Francia. Concepto que en Relaciones Internacionales se conoce como equilibrio de poderes. Este equilibrio surge en la Europa del siglo XIX porque los Estados europeos independientes, cada uno con poderes relativamente iguales, temían el surgimiento de un solo Estado (Hegemón) entre ellos (Mingst, 2007, p. 68). En 
particular, España percibe un peligro en la relación inglesa - portuguesa para conservar su hegemonía sobre sus territorios en el nuevo continente que iba desde el centro y hacia el sur de América, pero a su vez Inglaterra percibe una amenaza con Francia para mantener el dominio sobre el territorio norteamericano.

En el entorno, Europa ha sido sacudida con los mensajes provenientes de la Ilustración (siglos XVII - XVIII), movimiento posterior a la época conocida como El Renacimiento, y en donde el hombre cuestiona su ubicación en el universo y cuestiona la existencia de personas en un escalafón casi supranatural. Estos cuestionamientos se reflejan en la cultura inicialmente y trascienden para impactar en lo más profundo de las estructuras sociales y políticas, generándose en consecuencia una lucha entre conservar el absolutismo y dar paso al poder representativo.

Así pues, España comienza una dura batalla para mantener el statu quo adquirido a raíz del descubrimiento de América, generando un gasto exagerado en sus finanzas que trata de compensar con medidas impositivas sobre sus colonias. Inglaterra comienza la lucha por mantener el norte de América, y en Francia la monarquía decide apoyar el movimiento independista de los Estados Unidos, mientras que en su interior se gestaban movimientos de insurrección sobre la base de la igualdad del individuo, la noción de ciudadano y la división del poder.

Particularizando la situación de España, por estar directamente ligada a América Latina, las ideas de la Ilustración y la carga impositiva, generan una creciente expresión emancipadora, de separación, no necesariamente independista (es el caso de Colombia y su mal llamado Grito de Independencia, pues ciertamente mantenía cierto respeto hacía el monarca español). En el entorno ya se conocía de la independencia de los Estados Unidos y de la Revolución Francesa, quienes con lo acaecido habían esparcido de norte a sur y a través del océano los derechos del hombre en América, siendo una invitación a integrarse a un nuevo sistema de gobierno y a una nueva estructura, el llamado Estado Moderno.

La Constitución de España de 1812 pretende contrarrestar los efectos en los territorios hispanoamericanos de aquellos sucesos, acercándolos mediante la figura de una nación española que reúne a los españoles de ambos hemisferios (reconoce a los colonos como tales), estableciendo un derrotero constitucional de una España integrada por los territorios tradicionales y el de sus colonias, una representación y una distribución de poderes. (Constitución de Cádiz, 1812).

En otras palabras, el absolutismo de Fernando VII parece ceder y se van asentando con mayor fuerza ahora sí, los deseos independistas de algunos, observándose el surgimiento de las diferencias que marcaron el nacimiento de los países hispanoamericanos y con consecuencias hasta nuestros días: seguir dependiendo o ser nuevas naciones, centralismo o federalismo; lo cual sabiamente reflejaría Simón Bolívar en su discurso de Angostura (1819), al referirse a América como "dispersa en medio del mundo antiguo", cuando pedía instituciones propias de las nuevas naciones y no copias de aquellas a las cuales habían estado atadas (Bolívar, 1978).

Distinto camino corre Portugal, que en aras de evitar la invasión de la Revolución Francesa, optó por trasladar su monarquía, su imperio, su reino, a sus territorios brasileros y ejercer en él su poder; es por ello que el movimiento independista de estos se diera diferente a la América controlada por España y también posteriormente en el tiempo. 
Consolidada la independencia de la mayoría de los territorios latinoamericanos, pero no su unificación, la injerencia extranjera se mantuvo, no solo por parte de países europeos como antes, sino también de Estados Unidos. La Doctrina Monroe (1823) es presentada como una política de un estado redentor que, bajo amenaza, buscaba aislar la intervención de otras naciones sobre América Latina, pero en realidad era una cuestión de proteger sus propios intereses: "América para los americanos", recordando las célebres frases de James Monroe, 1823. Se advierte que la doctrina solo se pudo hacer efectiva hasta casi finales del siglo XIX, debido a la propia dificultad interna de los norteamericanos, en especial su guerra civil.

Durante este contexto histórico, en la ruina económica, con conflictos internos de división, la pérdida de sus territorios hispanoamericanos, España deja de ser el gran imperio mundial y surge como tal el británico, basado sobre dos aspectos básicos: el dominio del mar - quizás por la misma naturaleza de su territorio insulary la revolución industrial.

El imperio británico astutamente no optó, por lo menos en esta parte del mundo, por conquistar los que fueran territorios españoles, pero sí controlar enclaves territoriales para sus redes comerciales, permitiéndose además intervenir en asuntos propios de las nacientes repúblicas latinoamericanas, como por ejemplo su rol protagónico en conflictos bélicos como la denominada guerra de la triple alianza que enfrentó a Argentina, Brasil y Uruguay, como coalición, contra Paraguay, entre 1865 y 1870, la cual respondió a intereses británicos y a la búsqueda de acabar con un modelo autónomo de desarrollo del país guaraní.

No olvidemos que desde antes los ingleses apoyaron movimientos independistas en contra de España, y en el mar fueron grandes enemigos de esta. Casi concomitantemente con la intervención británica, España hizo algunos intentos de intervención y tal vez de recuperación territorial que fracasaron y que por el contrario afianzaron el rompimiento con los ahora países hispanoamericanos.

De importante mención es el proceso migratorio que se da hacia Latinoamérica, principalmente en Argentina y Brasil desde Europa y Asia, lo cual originó un cambio étnico, en la que se entrelazaron indígenas, africanos, europeos, mestizos, generando más diferencias en los territorios independizados y que ahora se reflejan en la variedad multiétnica que convive en las urbes de estos países.

En conclusión, ciertamente América bajo el lema "viva el Rey abajo el mal gobierno" expresó a finales del siglo XVIII su deseo autonomista, pero a la vez su fidelidad con la monarquía española, no obstante los cambios producidos desde la propia Europa y muy particularmente las ideas surgidas con la Revolución Francesa y aquellas que ya venían con la independencia de los Estados Unidos, amén del propio descontrol español en su intento de enfrentar a su principal rival, Inglaterra, lo que fue generando el paso de insurrecciones a movimientos independistas, más allá de las pretensiones de la Constitución Política de 1812 de reconocer a los pueblos hispanos como españoles, lo que no bastó, pues además Fernando VII cometió el craso error durante su régimen absolutista de ignorar aquellas primeras manifestaciones de insubordinación y aquellos ideales constitucionalistas que de a poco fueron calando en territorios que además fueron bastante susceptibles de aceptar la injerencia extranjera, antes y después de la independencia, con lo cual España no solo perdió sus territorios sino que se vio imposibilitada de recuperar. 


\section{La Independencia de Cuba y el nuevo Pan-Hispanismo.}

Con la entrega de España a los Estados Unidos de Cuba, Puerto Rico y Filipinas se da la estocada final al imperio español, y sin duda supone aceptar que aparece en el orbe un serio candidato para ser potencia mundial, cosa que consolidará durante el siglo XX. La estructura internacional emerge de la coexistencia de las unidades políticas de una época dada (Pérez, 2012, p. 53), en el juego por el poder internacional, tradicionalmente determinado por las potencias e imperios del Viejo Continente, surge un poderoso nuevo actor extra europeo.

A fines del siglo XIX el escenario regional cambia. Las amenazas de intervenciones de España, Francia o incluso Gran Bretańa comienzan a disminuir debido a la consolidación de Estados Unidos como potencia del continente, lo que es expresado en su creciente intervencionismo y gran expansión económica. (Briceño, 2014)

Incluso, desde antes, Estados Unidos ya había dado muestras de sus intenciones de interferir en los asuntos económicos de los pueblos latinoamericanos. Se posicionaba como líder comercial de esta vasta región, ahora solo faltaba dar una demostración de poderío militar, de ahí que el episodio del Maine-buque norteamericano que explotó en las costas de Cuba en 1898- fue la excusa de una intervención norteamericana en la isla, en detrimento de una España que consideraba vital conservar las últimas colonias para su sostenimiento económico, pero era claro también que España una vez más se había equivocado en su forma de manejar las disputas más que territoriales de sus colonias: de nuevo se habían impuesto cargas tributarias y quiso reprimir la insurrección, pero en este caso el riesgo era mayor que antes, habida cuenta de la existencia de una emergente potencia que requería del enclave cubano y puertorriqueño para sus intereses particulares y que por ende iba a tomar partido a favor de los colonos.

El interés de los Estados Unidos era tal, que en varias oportunidades hizo ofertas de compra, negadas por supuesto, pero bajo el pretexto del hundimiento de un barco estadounidense anclado en la bahía de la Habana, de la que se acusó -sin mayores pruebas- a los españoles. Washington declaró la guerra a España (Del Pozo, 2002, p. 64).

El conflicto cubano culmina con un llamativo tratado de paz entre España y Estados Unidos, en el que, entre las cuestiones pactadas, el país ibérico no solo renuncia a la soberanía sobre Cuba sino que termina cediendo, como antes se dijo, a Puerto Rico y Filipinas, aceptando a cambio una especie de indemnización, con lo cual se demuestra su paupérrima situación económica, pero además la ausencia de líderes, tan necesarios en momentos críticos.

Es interesante también entender la reacción de otros países europeos, durante el surgimiento y desarrollo del conflicto español con Estados Unidos. Fueron infructuosas algunas solicitudes espańolas de apoyo, lo cual para Europa sería un error estratégico de cara a la dominación mundial, pues no se observó que en el horizonte asomaba una nueva potencia. Muy poco valieron manifestaciones como la de Guillermo II de Alemania (1859 - 1941), e incluso de países hispanoamericanos que entendían la existencia de lazos comunes con Espańa y no con los norteamericanos; es más, desde el propio territorio español surge una nueva generación que observa la pertinencia de estrechar por medio de la 
cultura y la academia los lazos con ambos continentes, extendiéndose posteriormente a otras áreas como la jurídica o la comercial.

Casi a la par, nace la Unión Panamericana, que desarrollaría el colonialismo norteamericano:

Después del fracaso de la tentativa de Bolívar de construir una confederación de las naciones del Nuevo Mundo (congreso de Panamá de 1826), y de otras más infructuosas aún, una conferencia Panamericana se reunió en 1889 por iniciativa de los Estados Unidos. La conferencia limitó al comienzo sus objetivos al campo comercial, y creó una oficina que en 1910 se constituyó en la Unión Panamericana, y que fue el origen de la actual Organización de los Estados Americanos (OEA). (Álvarez, 2006, p. 154)

A la par también de acciones contundentes como la promoción de la independencia de Panamá de Colombia, o la facultad de intervenir en los países del Caribe si no pagaban la deuda. Sin olvidar también la Constitución de Cuba, en la que de manera abierta se le exige el pago a los cubanos por la ayuda en su independencia, se expresa la posibilidad de intervención norteamericana en cualquier momento, el control en sus asuntos económicos, se le impide adquirir deuda pública en ciertas circunstancias, se le limita la celebración de tratados o convenios internacionales, interviene en planes de salud -que más que favorecer a la población cubana apuntaba a proteger a los residentes y comerciantes norteamericanos en la isla-, y la utilización de los territorios carboneros y navales a favor de Estados Unidos, entre otros.

En síntesis, con la independencia de Cuba llega el fin absoluto del imperio espańol, nace el imperio inglés, pero comienza a emerger el gran imperio norteamericano, mismo que más tarde se verá reflejado en el mundo con la imposición de su moneda en las actividades económicas de todo el orbe, surge su poderío militar, aquel que será la base para su injerencia en cuanto conflicto mundial se dé, no en vano y mencionando unos pocos, los Estados Unidos han intervenido en las llamadas Guerras Mundiales, como también en Vietnam, en Honduras, en el Salvador, en Panamá, en Nicaragua, en Colombia, en Irán, en Kuwait, en Irak, en Afganistán, en Israel, etc.

Pero la independencia de Cuba también significó una nueva mirada de los países hispanos hacia España. Se consolida el uso de la lengua española como factor de unión, los conflictos y resentimientos son cambiados por la cultura y la academia, lazos que han perdurado y que hoy se evidencian cuando España asume la vocería de algunos países latinoamericanos ante la Unión Europea.

Por lo tanto, de lo anterior, surgen en América dos visiones y categorías de análisis, que desde el punto de las Relaciones Internacionales, y más específicamente, desde el estudio de la integración latinoamericana, ayudan a entender las orientaciones políticas de cada una de las tendencias integracionistas: el panamericanismo y el latinoamericanismo:

Dos tendencias contrapuestas se han imbricando en la evolución de nuestros países, a partir de su constitución como unidades políticas independientes, en el primer cuarto del siglo XIX: la latinoamericanista y la panamericanista: la primera, defensiva y de inspiración bolivariana, y la segunda, con soporte en la doctrina Monroe (1823), formulada para asegurar la penetración y el dominio hemisférico por parte de Estados Unidos. (Báez, 2007, p. 130). 
Recordando, que estas categorías de análisis no se contraponen sino que se complementan con otras categorías de análisis, que si bien no descuidan el componente político, se centran más en las características económicas y comerciales de los procesos de integración, tales como el regionalismo abierto, regionalismo abierto renovado (Gonzalez, Duarte, \& Montoya, 2014) y regionalismo y lo que recientemente ha acuñado post-liberal (Sanahuja, 2014).

\section{Las Relaciones Internacionales en América Latina en el siglo XX convulsionado. Latinoamérica en las Guerras Mundiales.}

En medio de una economía dedicada a la exportación de materias primas y el inicio de un largo proceso de endeudamiento para financiar su naciente industria, los países latinoamericanos se ven altamente afectados con ocasión de la Primera Guerra Mundial, pues en ella se encontraban involucrados varios de los países a los cuales se destinaban sus productos exportados, dando de paso la oportunidad para que los Estados Unidos consolidaran su influencia sobre el continente y su poderío económico se acrecentara; al fin y al cabo los norteamericanos participaron tanto en la Primera como en la Segunda cuando ambos conflictos ya avanzaban, pero en territorios europeos, lo que permitió que sus industrias siguieran produciendo y el sector financiero se sobrepusiera a la crisis de 1929 o Gran recesión.

Con la Primera Guerra Mundial no solo se asiste a una alteración en el equilibrio del orden internacional, sino también de un nuevo orden económico en el que se desmorona Inglaterra y Estados Unidos da inicio a su papel de líder orbital, que consolidaría al término de la Segunda Guerra Mundial, al ser la única potencia que no sufrió daños en su estructura económica y productiva. Los países de América Latina, como Argentina y Brasil, que dependían casi de forma directa del mercado europeo para el financiamiento de su balanza de pagos, se vieron afectados tras la exigencia de la cancelación de los préstamos por parte de los bancos de propiedad privada, lo que provocó una crisis interna, más allá de que algunos países se vieran beneficiados por las exportaciones de productos muy propios del consumo bélico, como en el caso de Venezuela con el petróleo o Chile con el nitrato.

Ya para la Segunda Guerra Mundial, la situación económica en América Latina se complica aún más, porque dada la escasez de productos importados de Europa -por encontrarse de nuevo sus proveedores en guerra- se crean pequeńas industrias de muy mala calidad pero que permiten satisfacer la demanda interna (Leillen, 2010); aunque en medio de una creciente inestabilidad social y el avance de factores comunistas, las naciones se encuentran divididas entre simpatizantes de los aliados y de los movimientos fascistas, lo cual golpea directamente a esa incipiente producción.

Luego del ataque japonés a Pearl Harbor (7 de diciembre de 1941), comenzó la presión de Washington para que Latinoamérica, tras una fase neutral, se adhiriera a la causa de su mayor financiador, Estados Unidos, pero sin que ello representara conflictos de interés en territorios americanos. No obstante, vale la pena mencionar que Brasil contó con hombres y naves en el enfrentamiento (Guilherme \& Lopez, 2009, p. 571). 
El entusiasmo político por hacer parte de la Sociedad de las Naciones (1919) -organización creada mediante el Tratado de Versalles, que estableció las condiciones de los derrotados de la Primera Guerra Mundial y fijó pautas de comportamiento estatal con el fin de evitar futuros enfrentamientos-, fue una muestra de una errada participación de los países de América Latina, pues creyeron encontrar allí una aliada para frenar la intervención norteamericana y un mediador en sus conflictos fronterizos, algo habitual en los comienzos del siglo XX.

Esta organización, presentada bajo una orientación teórica idealista dentro de las Relaciones Internacionales, poco trascendería frente al mundo en general por la negativa norteamericana a hacer parte de ella, pues al fin y al cabo ya se consolidaba su dominio universal, ratificado al término de la Segunda Guerra Mundial, cuando aparecería como salvador de los arruinados países europeos, hasta el punto de lograr que desapareciera el patrón oro y el dólar asumiera su posicionamiento a nivel mundial.

Incluso, ni la política de Roosevelt del Buen Vecino (1933), evitó que se aumentaran las diferencias de los países latinoamericanos con el país del norte; las mismas no solo ya estaban sentadas, sino que eran evidentes desde lo social, industrial, militar y económico.

\section{La Guerra Fría en Latinoamérica}

El término 'guerra fría' fue por primera vez utilizado por el escritor español Don Juan Manuel en el siglo XIV, denotando la interminable rivalidad en España entre cristianos y árabes (Halliday, 1994). En su acepción moderna fue acuñado por Bernard Baruch, consejero del presidente Roosevelt, quien utilizó el término en un debate en 1947 y fue popularizado por el editorialista Walter Lippmann, para designar la larga y abierta rivalidad que enfrentó a los Estados Unidos y la Unión Soviética y sus respectivos aliados tras la Segunda Guerra Mundial (Lozano, 2012, p. 404). Los acontecimientos posteriores hasta 1945, consolidaron los centros del poder mundial en Estados Unidos y la URSS, nada raro con una Europa en reconstrucción, un imperio japonés humillado y un 'tercer mundo' irrelevante en la práctica política internacional (Niño, 2008), dando inicio a la denominada Guerra Fría. Este conflicto fue la clave de las Relaciones Internacionales mundiales durante casi medio siglo y se libró en los frentes político, económico y propagandístico, pero solo de forma muy limitada en el frente militar (Ocaña, 2003)

El sistema tiende siempre a ordenarse, inevitablemente, a partir del interés de las grandes potencias, es decir, de los estados que más poder tienen (Gullo, 2010, p. 27). En ese orden de ideas, tras la Segunda Guerra Mundial algunas cosas quedaban evidentes: Estados Unidos asumía de manera definitiva su hegemonía sobre el mundo occidental; otra, consecuencia lógica de la anterior, el mundo se dividía, y del otro lado estaba la Unión Soviética. Adicionalmente, dos ideologías, dos sistemas económicos, dos formas de gobernar, es decir, se consolidó una nueva distribución del poder internacional que dio origen al sistema bipolar.

En este nuevo contexto internacional, casi de forma natural, América Latina, es considerada como zona de influencia de los Estados Unidos, lo que en esencia convierte a esta región, por convicción o por obligación, en un aliado incondicional de 
los norteamericanos, con las excepciones que supondría Cuba y alguno que otro intento fallido de penetración socialista en territorios americanos.

Algo que pareció desconocerse y que solo con el transcurrir del tiempo se fue probando, era que la Unión Soviética, entre sus objetivos iniciales, no tenía en mente la conquista del mundo, pues lo que priorizaba era su propia seguridad. Para Estados Unidos, por su parte, era la estrategia de la contención -o "containment policy"que definía sus objetivos y se resumían en la idea de impedir todo avance del comunismo, al cual se identificaba con la URSS.

La Guerra Fría significo para gran parte de América Latina una pérdida considerable de autonomía: se presentó como un importante condicionante externo, que incluso en algunos países latinoamericanos facilitó intervenciones directas e indirectas, de las cuales se destacan las siguientes:

Cuadro No. 2: Intervenciones

militares de Estados Unidos en estados americanos en período de Guerra Fría

\begin{tabular}{|c|c|}
\hline País & Año \\
\hline Guatemala & 1953 \\
\hline Panamá & 1964 \\
\hline República Dominicana & 1965 \\
\hline Guatemala & $1967-1969$ \\
\hline Granada & 1983 \\
\hline Panamá & 1989 \\
\hline
\end{tabular}

Fuente: Elaboración propia.

No obstante, se encuentran una serie de intervenciones indirectas e influencias en procesos políticos de la Región: el desembarco en Bahía Cochinos, en Cuba; el apoyo en diversos golpes militares como en Chile, Brasil, entre otros tantos; el apoyo a los 'contras' en Nicaragua y el Salvador; el mantenimiento por parte de Estados Unidos de la dictadura de la familia Duvalier durante 30 años en Haití, entre otras actuaciones condicionantes.

Lo anterior, también enmarcado ideológicamente en la noción de la seguridad nacional aunada a la Doctrina Truman de marzo de 1947, que afirmó que la política de los EE.UU. debía consistir en apoyar a los pueblos libres que se resistieran a todos los intentos de dominarlos, ya fuera por medio de minorías armadas o por medio de presiones exteriores, algo que se mira como paradójico si se entiende que en América Latina la historia de la norma de "no intervención" está íntimamente ligada al proceso mismo de su independencia, a pesar de los propios intentos norteamericanos como la antes expuesta Doctrina Monroe.

Lo lógico de la Doctrina Truman es que antes de pensar en la seguridad nacional de los países latinoamericanos, la misma era un pretexto para asegurar la hegemonía de Estados Unidos en el continente, que con el transcurrir del tiempo se convirtió en constantes y funestas intervenciones en los asuntos de las demás repúblicas americanas.

Si bien estas acciones precipitaron una conciencia colectiva antiimperialista y el anhelo de no permitir la intervención, caso de la Novena Conferencia Panamericana (Bogotá, 1948), en la que básicamente se promulga que los derechos fundamentales de los estados no son susceptibles de menoscabo alguno y que el territorio de un estado es inviolable, no puede ser objeto de ocupación militar ni de otras medidas de fuerza (Organización de Estados Americanos, 2013). La realidad demostró que pudo más el concepto de seguridad nacional y los intereses de evitar la expansión de las ideas comunistas en los pueblos centro y sur de América. 
Sistemáticamente la política de los Estados Unidos se valió de dos instrumentos adoptados por la comunidad interamericana en 1947 y 1948: el Tratado Interamericano de Asistencia Recíproca (TIAR) y la Organización de los Estados Americanos (OEA). Los Estados Unidos posiblemente los veían como parte de su estrategia anticomunista. En la conferencia de Río de Janeiro de 1947, en la que se crea el TIAR, también se establece una ambigua cláusula: si la independencia, modelo político o integridad territorial de un Estado estaba en peligro (aun aunque no mediase violencia o amenaza de invasión en ese proceso), estaba igualmente justificada la intervención en el estado en cuestión.

Adicionalmente, la Alianza para el Progreso (1961 - 1970), aunque era vista desde lo económico, se convirtió en otro instrumento para la consolidación norteamericana y de injerencia directa en los demás países del continente, pregonando su ayuda para América Latina.

Es menester señalar que en medio de una creciente estructura social desigual, malos gobiernos, inestabilidad económica y otros factores que afectaban directamente a la masa popular, las ideas socialistas sí fueron calando en algunos nacionales latinoamericanos, de ahí que incluso movimientos políticos por la vía democrática accedieron al gobierno en sus respectivos países, lo cual fue visto por Estados Unidos como una amenaza a sus dominios, por ello, en ocasiones, el intervencionismo permitió y facilitó la instauración de dictaduras militares aún en detrimento de sus propias bases independistas que le hicieran ser el país de las oportunidades y de la libertad; al fin y al cabo el éxito de la revolución cubana en 1959 era una prueba bastante cercana de penetración extranjera en sus intereses.

La Guerra Fría, la bipolaridad, ahondaba en definitiva la idea de que América Latina debía integrarse en el bloque capitalista: ya había antes declarado su apoyo a los países aliados, ya era evidente su necesidad económica con los Estados Unidos, era un hecho la hegemonía de este en gran parte del mundo, en consecuencia había también la necesidad de enfrentarse a la subversión comunista. Latinoamérica debía seguir la senda de Occidente y del anticomunismo, entendiendo por comunismo lo que pusiera en entredicho cualquier aspecto del mundo occidental, cualquier oposición, sin olvidar además que en el continente las élites económicas, políticas y militares, también respondían a ritmos propios, a intereses particulares, por lo que era muy difícil que terminaran cediendo fácilmente a la política de la Unión Soviética en contra de la norteamericana.

Por lo anterior, los condicionamientos externos en materia política, militar y económica, de la mano de la alianza del progreso y la inserción al bloque capitalista, significaron importantes reducciones del margen de autonomía, en diferentes proporciones, de los países latinoamericanos, $y$ en ese sentido, su nivel de autodeterminación también fue muy bajo.

\section{La década de los 80: obstáculo a los planes autonomistas}

Otra importante coyuntura internacional, que resultó en nuevos condicionamientos y pérdida de capacidad de autodeterminación de los países latinoamericanos, ha sido la denominada década perdida de los años 80, o también conocida como la crisis de la deuda. Tal período ha sido el episodio económico más traumático que ha experimentado América Latina a lo largo de su historia. Durante "la década perdida" a la cual dio lugar, América Latina retrocedió 
del $121 \%$ del promedio del PIB per cápita mundial al $98 \%$, y del $34 \%$ al $26 \%$ del PIB por habitante de los países desarrollados (Ocampo, Stallings, Bustillo, Velloso, \& Frenkel, 2014).

Si bien las causas estructurales de la crisis de la deuda en América Latina se reconocen principalmente desde la década anterior (los desequilibrios macroeconómicos internos y choques externos, tanto en los precios de los hidrocarburos como en la disponibilidad y costo del financiamiento externo), es a inicios de los años 80 cuando la crisis se hace evidente y conduce a la región, con diferentes matices, a un período traumático con grandes efectos económicos, sociales y políticos.

Esta etapa, tal como señala Ricardo French Roberto Devlin (1993), marcó de forma indeleble a la sociedad latinoamericana: retrasó drásticamente el crecimiento económico y derribó el modelo basado en la sustitución de importaciones y la intervención estatal. En una muestra más de carencia de un margen importante de autonomía, la región tuvo que ceder ante el dictado de la reforma neoliberal, que desmanteló la burocracia estatal históricamente propiciada por la doctrina de la Comisión Económica para América Latina y el Caribe (Wollrad, Maihold, \& Mols, 2011)

\section{Nuevos horizontes de las Relaciones Internacionales en América Latina. Procesos de integración en los años 90 y el comienzo del siglo XXI}

El proceso de integración europeo iniciado con posterioridad a la Segunda Guerra
Mundial, sin duda constituye un ejemplo para los países de América Latina, en particular la transición española hacia la democracia tras la muerte del general Francisco Franco (1892 - 1975), y su ingreso a la comunidad europea (décadas 70 y 80 ), que constituyen influyentes elementos para dar fin a los regímenes dictatoriales a los cuales se vieron sometidos entre los años 50 y 80 , y dar inicio a una idea concreta de establecer procesos de integración (Cardona G., 2010).

Bajo este contexto han surgido organizaciones de carácter económico como el Mercado Común Centroamericano (CARICOM), Comunidad Andina, MERCOSUR, UNASUR, Alianza del Pacífico, amén de otras organizaciones de carácter político como el Parlamento Andino, Comisión Parlamentaria Conjunta de Mercosur, Iniciativa Bolivariana para las Américas, Comisión Amazónica Permanente, Parlamento Centroamericano, Parlamento Latinoamericano y el Parlamento Indígena de América. Por lo tanto, si bien con diferentes grados de institucionalidad y funcionalidad, en cuanto a las dinámicas del Sistema Internacional, América Latina, no fue ni ha sido ajena a la proliferación de iniciativas integracionistas fomentadas por diversas organizaciones internacionales, desde la segunda mitad del siglo XX.

Con la Unión Europea (UE), y consolidado el regionalismo abierto desde la década de los 90, termina el siglo XX y se inicia el siglo XXI con nuevas relaciones para América Latina y, de alguna manera, una vía de escape a su dependencia de los Estados Unidos. Incluso se ha generado la firma de convenios de integración económica sin importar los niveles de desarrollo de los suscribientes, como es el caso de los acuerdos de asociación entre la Unión Europea y México o Chile, o entre la UE 
y otros procesos de integración como Mercosur, SICA y la Comunidad Andina, los cuales se consideran acuerdos de tipo integral o de asociación, por estar constituidos sobre tres pilares fundamentales: diálogos políticos, cooperación y comercio.

A decir, los acuerdos de asociación "superan la naturaleza y alcance de los Acuerdos Marco de Cooperación que utiliza generalmente la Unión Europea para sus relaciones con terceros países o agrupaciones, y que en el caso de los antes citados existen semejanzas" (Grisanti, 1999):

Es una Asociación, es un Acuerdo bilateral, es global, es estable, es evolutivo y es mixto [...] Las negociaciones de los acuerdos de diálogo político y de cooperación anteceden, por lo general, a los Acuerdos de Asociación y los tratados de libre comercio que los componen. Esto es lo que sucede con la Comunidad Andina, que ya tiene suscrito con la Unión Europea, desde diciembre del 2003, un Acuerdo de Diálogo Político y Cooperación, que involucra una amplia variedad de temas: la agenda de trabajo de este acuerdo comprende cinco grandes rubros: democracia y gobernabilidad, comercio y desarrollo social, nuevas amenazas, migraciones, medioambiente y diversidad biológica. (Leiva, 2012, p.40)

\section{Evolución de las relaciones latinoamericanas con España}

Las relaciones de España con Latinoamérica no solo se limitan a su papel de miembro integrante de la Unión Europea, aunque es innegable su intervención en el rápido y exitoso proceso de posicionamiento inversor de Europa en América Latina, provocando incluso la reacción de Estados Unidos de poner en marcha el ALCA y de expandir el NAFTA.

España y los países latinoamericanos tienen suscritos múltiples tratados bilaterales de comercio y a su vez en conjunto hacen parte de la Cumbre Iberoamericana, reunión anual de Jefes de Estado y de Gobierno de los 22 países de América Latina y Europa de lengua hispana y portuguesa, integrando la Conferencia Iberoamericana de Naciones, foro de consulta y concertación política cuyo propósito es reflexionar sobre los desafíos del entorno internacional (Jarque, Ortiz, \& Quenan, 2009), así como impulsar la cooperación, coordinación y solidaridad regionales. Desde una perspectiva española, académicos como Celestino del Arenal considera que a lo largo de los siglos y por la interacción entre España y América Latina se ha logrado configurar una suerte de identidad iberoamericana, cuyo autor español denomina "la iberoamericanidad" (Del Arenal, 2011), cuyas herramientas de acción de política exterior por excelencia son la Cooperación Internacional para el Desarrollo y la Cumbre Iberoamericana.

Entre los principios y compromisos rectores adoptados por la Cumbre se encuentran:

- El respeto al derecho internacional, la soberanía, la no intervención y al derecho de cada pueblo a construir libremente en paz, estabilidad y justicia su sistema político y sus instituciones.

- La obligación de resolver las controversias internacionales por medios pacíficos.

- La consolidación de la democracia y el fortalecimiento de los mecanismos para garantizar el respeto a los derechos humanos y las libertades fundamentales (Cumbre Iberoamericana, 2014) 
Entre los casos puntuales en las relaciones entre España y Latinoamérica, Vicente Torrado Trinidad en su documento "La inmigración latinoamericana en España” (2005), destaca que el gran incremento en el número de personas de origen latinoamericano afincadas en el país ibérico que se está registrando desde el año 2000 puede argumentarse, entre otras razones, por el cambio de coyuntura sociopolítica vivido en España en las dos últimas décadas, el acelerado crecimiento de la economía española experimentado principalmente desde mediados de la década de los noventa, el desarrollo de su política migratoria (con continuos procesos de regularización), la firma de acuerdos bilaterales para regular los flujos migratorios con Colombia, Ecuador y la República Dominicana, y la mejor valoración y aceptación que la población española muestra en todas las encuestas hacia la población procedente de Sudamérica (dados los vínculos históricos y la mayor semejanza cultural, lingüística, religiosa, etc.) frente a otros grupos de inmigrantes como pudieran ser árabes y musulmanes, amén de los flujos de arrastre, esto es, de la reunificación familiar.

Advirtiendo sí, que este fenómeno sufrió un importante efecto de retorno a raíz de la crisis financiera del año 2008, cuando muchos inmigrantes quedaron desempleados en España y optaron por regresar a sus naciones originales.

Los acercamientos entre América Latina y España durante el presente siglo, ciertamente se han visto golpeadas con algunas manifestaciones antiespañolas que han provenido de gobiernos venezolanos y líderes de Bolivia, Ecuador, Nicaragua y Cuba principalmente, pero que no pueden calificarse como un pensamiento generalizado de los países latinoamericanos ni su población, pues como resultado final han pesado más los lazos de integración aunados a los vínculos históricos, lingüísticos, culturales y religiosos.

\section{Comparativo de la integración europea y de la integración en América Latina}

Es menester señalar que la integración como proceso originalmente se enmarcó estrictamente dentro de un carácter económico, básicamente a través de la figura de convenios de integración económica y de allí que en general los procesos fueron subregionales, puesto que los procesos parten de la liberación del comercio bilateral y, para esto, la ventaja radicaba en la cercanía geográfica.

No obstante, algunas excepciones a esta ventaja como el Consejo de Ayuda Mutua Económica (CAME), que afiliaba a los países socialistas de la órbita soviética, fueron marcando un nuevo rumbo y hoy ya el factor geográfico de cercanía no es tampoco el único elemento, por lo cual se habla de regionalismo abierto, convirtiéndose en un proceso que pasa de la integración económica a negociaciones interregionales.

Otra característica importante de los convenios en sus orígenes fue la relativa uniformidad en los niveles de desarrollo socioeconómico de los países signatarios de los diferentes pactos, como en el caso de la Unión Europea, institución multiestatal que abarca únicamente a los países desarrollados de Europa Occidental, y aquellos países que han ingresado con posterioridad a 1970 han tenido que realizar ciertos ajustes económicos de carácter interno, con el fin de garantizar la estabilidad del bloque.

Sin embargo, el regionalismo abierto, como herencia de los denominados tigres asiáticos, se abre paso en América Latina 
desde la década de 1990, también por los cambios configurados en la región por el fin del bipolarismo. En este orden de ideas, el regionalismo abierto ha permitido la firma de convenios de integración entre países de diferentes niveles de desarrollo, rompiendo así la característica de la simetría o niveles similares de desarrollo, propios de viejo regionalismo. La integración de Estados Unidos con países latinoamericanos y los tratados de libre comercio entre la Unión Europea y otras naciones, muestran la heterogeneidad como un nuevo cambio en la dinámica de los procesos de comercio bilateral.

Lo expuesto bien lo explica Alfredo Guerra (2008): a todas luces era contradictorio el auge de los acuerdos de integración (opción restrictiva del multilateralismo) y el ingreso masivo a la OMC (opción multilateralista). Entonces apareció el regionalismo abierto.

Para mayor precisión, el siguiente cuadro comparativo destaca algunos procesos de integración latinoamericanos y el proceso de integración europea:

Cuadro No. 2: Comparativo de proceso de integración

Europea con los procesos latinoamericanos.

\begin{tabular}{|c|c|c|}
\hline $\begin{array}{l}\text { Principales } \\
\text { Aspectos }\end{array}$ & América & Europa \\
\hline \multirow[t]{2}{*}{$\begin{array}{l}\text { Principales } \\
\text { procesos de } \\
\text { integración }\end{array}$} & $\begin{array}{l}\text { Multiplicidad } \\
\text { Existen diversos grupos o bloques } \\
\text { de integración, entre los que se } \\
\text { destacan: } \\
\text { MERCOSUR, CAN, ALCA, G3, Grupo de } \\
\text { Rio, CARICOM }\end{array}$ & $\begin{array}{l}\text { Unicidad } \\
\text { Si bien aún no son miembros todos los países europeos, se } \\
\text { estructura como un solo bloque. } \\
\text { UE }\end{array}$ \\
\hline & $\begin{array}{l}\text { En el caso concreto de Mercosur, la } \\
\text { integración ha cumplido básicamente } \\
\text { dos etapas: esquema de cooperación } \\
\text { mutua y de liberalización comercial } \\
\text { (1984-1991). } \\
\text { Esquema integrativo de liberalización } \\
\text { y cooperación e introducen plazos } \\
\text { concretos para la realización del } \\
\text { mercado común (1991-1995). }\end{array}$ & $\begin{array}{l}\text { La Unión Europea nace y se establece como el compromiso } \\
\text { de cooperación e integración dentro de una estructura } \\
\text { múltiple (Comunidad Europea del Acero y el Carbón), } \\
\text { Comunidad Económica Europea, Euratom), siguiendo } \\
\text { por un proceso de integración paso a paso hasta que el } \\
\text { inicio de un nuevo estadio de integración (Zona de Libre } \\
\text { Comercio, Unión Aduanera, Mercado Común, etc.). Significa } \\
\text { la conclusión de la fase precedente. }\end{array}$ \\
\hline \multirow[t]{3}{*}{$\begin{array}{l}\text { Aspectos } \\
\text { jurídicose } \\
\text { institucionales }\end{array}$} & $\begin{array}{l}\text { Multiplicidad de convenios bilaterales } \\
\text { internacionales llevados como ley por } \\
\text { el legislativo de cada estado parte. } \\
\text { Ejemplo: TLC. }\end{array}$ & $\begin{array}{l}\text { Si bien la Unión Europea igualmente celebra convenios } \\
\text { con otros países, lo hace como un todo, un solo bloque en } \\
\text { relación a la otra parte que es un solo estado. }\end{array}$ \\
\hline & $\begin{array}{l}\text { Creación de uniones aduaneras a } \\
\text { partir de tratados de libre comercio. }\end{array}$ & $\begin{array}{l}\text { Creación de unión aduanera consignada en el Tratado } \\
\text { Original como un principio de libre práctica, luego } \\
\text { aprobación de un código común aduanero. }\end{array}$ \\
\hline & $\begin{array}{l}\text { La creación de normas que toman los } \\
\text { órganos de gobierno del MERCOSUR } \\
\text { deben ser ratificadas por los estados } \\
\text { miembros, por ende no hay creación } \\
\text { autónoma de derecho. }\end{array}$ & $\begin{array}{l}\text { Potestad del Parlamento Europeo en la creación de leyes de } \\
\text { alcance comunitario. }\end{array}$ \\
\hline
\end{tabular}




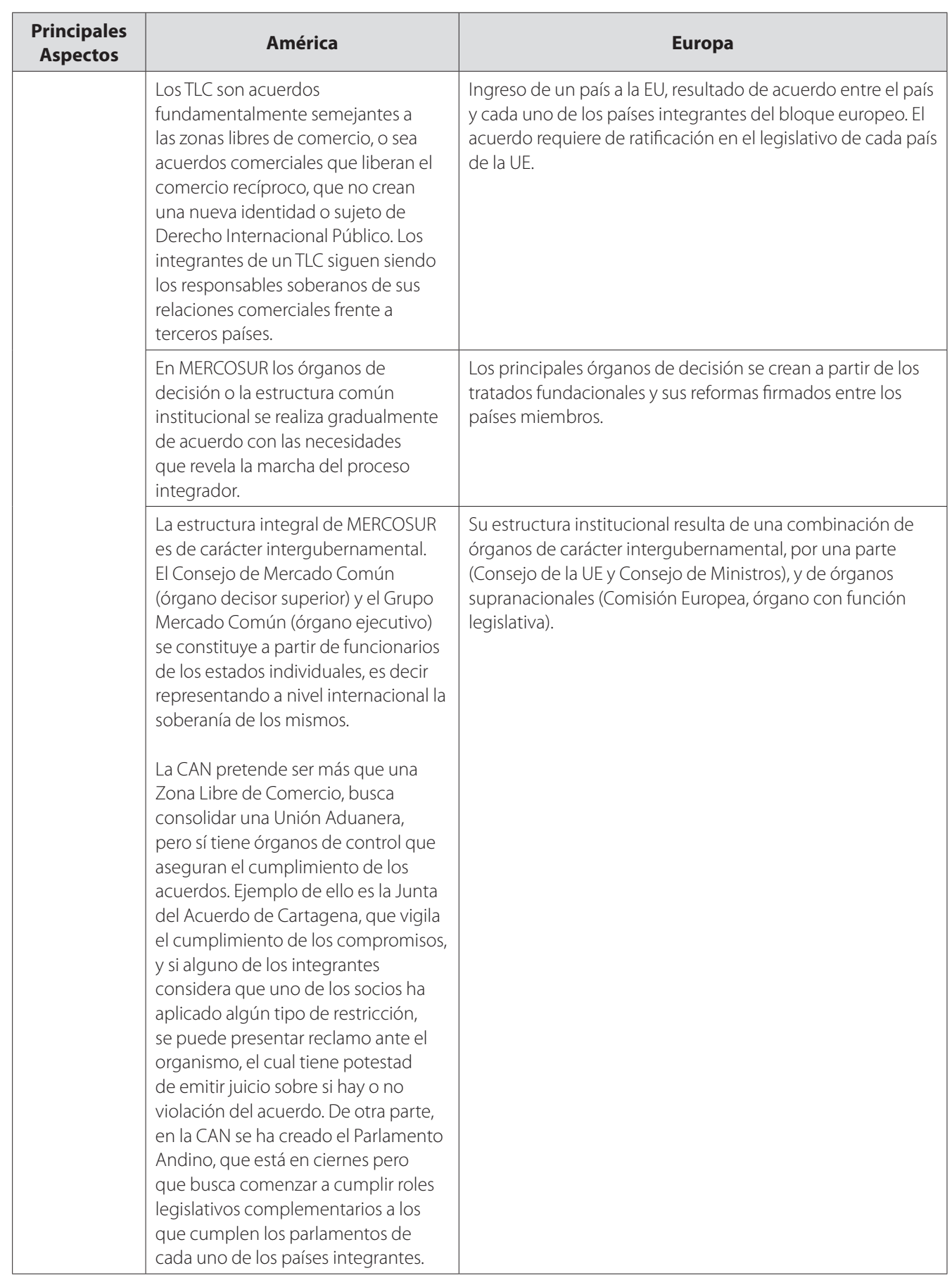




\begin{tabular}{|c|c|c|}
\hline $\begin{array}{l}\text { Principales } \\
\text { Aspectos }\end{array}$ & América & Europa \\
\hline \multirow[t]{5}{*}{$\begin{array}{l}\text { Dimensión } \\
\text { económica }\end{array}$} & $\begin{array}{l}\text { Acuerdos de comercio como fuente } \\
\text { posterior de cooperación. }\end{array}$ & $\begin{array}{l}\text { Proceso de Integración que combina Comercio con } \\
\text { Cooperación Económica. }\end{array}$ \\
\hline & $\begin{array}{l}\text { Asociación de procesos de efectos } \\
\text { económicos con procesos de } \\
\text { apertura comercial y de inversión } \\
\text { extranjera con respecto a terceros } \\
\text { países. }\end{array}$ & $\begin{array}{l}\text { Unión económica (etapa del proceso de integración en la } \\
\text { que se unifica todas las políticas inherentes a los vínculos } \\
\text { económicos: unificación del mercado de capitales, control } \\
\text { sobre la tasa de cambio, una sola moneda, eliminación de } \\
\text { los subsidios a la producción y la exportación y unificación } \\
\text { de los regímenes tributarios) }\end{array}$ \\
\hline & $\begin{array}{l}\text { Triangulación comercial: participación } \\
\text { de un país en más de un proceso de } \\
\text { integración al mismo tiempo. }\end{array}$ & \\
\hline & $\begin{array}{l}\text { Fase de integración latinoamericana } \\
\text { derivada de un modelo económico } \\
\text { de sustitución de importaciones. }\end{array}$ & $\begin{array}{l}\text { Igualdad de oportunidades para todas las empresas } \\
\text { comunitarias en la participación en licitaciones de carácter } \\
\text { público que se realicen en cualquiera de los países de la UE. }\end{array}$ \\
\hline & $\begin{array}{l}\text { Compromisos para la eliminación de } \\
\text { barreras al comercio recíproco. }\end{array}$ & $\begin{array}{l}\text { Unificación del mercado de servicios bancarios, de seguros } \\
\text { y de transporte. }\end{array}$ \\
\hline \multirow[t]{6}{*}{$\begin{array}{l}\text { Aspectos } \\
\text { políticos }\end{array}$} & $\begin{array}{l}\text { Integración a partir de negociaciones } \\
\text { bilaterales. }\end{array}$ & $\begin{array}{l}\text { Creación de bienes públicos (estructuras y sistemas que } \\
\text { sean del beneficio para todos los integrantes del proceso de } \\
\text { integración). }\end{array}$ \\
\hline & $\begin{array}{l}\text { Compromisos para la eliminación de } \\
\text { barreras al comercio recíproco. }\end{array}$ & $\begin{array}{l}\text { Eliminación total de las restricciones aduaneras y de los } \\
\text { controles de inmigración. }\end{array}$ \\
\hline & & $\begin{array}{l}\text { La libre circulación de capitales, con aplicación del régimen } \\
\text { de trato nacional, tanto en lo tributario como en lo } \\
\text { administrativo, para las inversiones intrarregionales. }\end{array}$ \\
\hline & & $\begin{array}{l}\text { La eliminación de las diferencias en los sistemas impositivos, } \\
\text { unificando los niveles de las tarifas fiscales (impuestos). }\end{array}$ \\
\hline & $\begin{array}{l}\text { Los TLC son acuerdos } \\
\text { fundamentalmente semejantes a } \\
\text { las zonas libres de comercio, o sea } \\
\text { acuerdos comerciales que liberan el } \\
\text { comercio recíproco, que no crean } \\
\text { una nueva identidad o sujeto de } \\
\text { Derecho Internacional Público. Los } \\
\text { integrantes de un TLC siguen siendo } \\
\text { los responsables soberanos de sus } \\
\text { relaciones comerciales frente a } \\
\text { terceros países. }\end{array}$ & $\begin{array}{l}\text { Consolidación de una política exterior Paneuropea, } \\
\text { mediante la unificación de criterios de política internacional. }\end{array}$ \\
\hline & $\begin{array}{l}\text { Mercado Común del Sur, aparece } \\
\text { a través de una fase de deterioro } \\
\text { político interno de los estados con } \\
\text { la necesidad de lograr estabilidad y } \\
\text { bienestar en la sociedad. }\end{array}$ & $\begin{array}{l}\text { La integración surge como medio de garantía y } \\
\text { consolidación de la paz continental luego de la Segunda } \\
\text { Guerra Mundial, como compromiso común de colaborar } \\
\text { mutuamente al bienestar general del continente y alcanzar } \\
\text { un equilibrio de poderes entre los estados europeos. }\end{array}$ \\
\hline
\end{tabular}




\begin{tabular}{|c|c|c|}
\hline $\begin{array}{l}\text { Principales } \\
\text { Aspectos }\end{array}$ & América & Europa \\
\hline \multirow{6}{*}{$\begin{array}{l}\text { Otros } \\
\text { Aspectos } \\
\text { Relevantes }\end{array}$} & & Fomento al sector agropecuario regional. \\
\hline & & Creación de fondos para proyectos comunitarios. \\
\hline & & $\begin{array}{l}\text { Políticas colectivas de infraestructura (dinámica de } \\
\text { expansión geográfica). }\end{array}$ \\
\hline & $\begin{array}{l}\text { En Mercosur el residente del país } \\
\text { integrante o asociado puede laborar } \\
\text { legalmente en los países del grupo. }\end{array}$ & $\begin{array}{l}\text { El libre movimiento de mano de obra tanto asalariada como } \\
\text { independiente. }\end{array}$ \\
\hline & $\begin{array}{l}\text { Mercosur posee un régimen } \\
\text { migratorio bastante privilegiado } \\
\text { para sus integrantes y para los países } \\
\text { asociados como Chile o Colombia: } \\
\text { por ejemplo, el derecho a tramitar mi } \\
\text { residencia. }\end{array}$ & $\begin{array}{l}\text { Eliminación total de las restricciones aduaneras y de los } \\
\text { controles de inmigración. }\end{array}$ \\
\hline & & $\begin{array}{l}\text { Temas relevantes de cooperación con políticas ambientales, } \\
\text { ciencia y tecnología. }\end{array}$ \\
\hline
\end{tabular}

Fuente: construcción propia con base en Vera-Fluixá (2000).

\section{Conclusiones}

La autonomía se constituye como un poderoso y vigente mecanismo, surgido y desarrollado en el interior de América Latina para analizar y caracterizar la evolución, el rol que ha jugado la región en el escenario internacional. Muestra de lo anterior son los últimos y constantes aportes y desarrollos en cabeza de académicos de diferentes latitudes de la región, ya no solo Argentina o Brasil, y ajustados a las realidades y contextos particulares tanto de la región como del sistema internacional, que han enriquecido de buena manera el acervo académico referente a la autonomía.

Quizás más que otras regiones del mundo, las Relaciones Internacionales de América Latina han estado marcadas por el momento histórico en que se encuentre. Incluso antes de la configuración en estados modernos, la importancia geopolítica y geoeconómica brindó un rol, no de jugador de primer orden, sino de territorios como objetos en la configuración del orden internacional determinado. También han sido factores determinantes: la debilidad institucionalidad, la incapacidad de un control pleno del territorio, la búsqueda infructuosa de industrialización que atravesó buena parte del siglo XX, el caudillismo político, existencia de élites políticas con intereses particulares y la carencia de un proyecto de nación coherente y de largo plazo.

Por lo tanto, si bien en la región latinoamericana, especialmente en el cono sur se identifican aportes teóricos en las Relaciones Internacionales, que propenden por políticas exteriores con mayor autonomía y capacidad de decisión, como los aportes de Juan Carlos Puig (1980), Rusell y Gabriel Tokatlian (2002), las Relaciones Internacionales de América Latina han sido en gran parte sumisas, guiadas durante su existencia por las políticas de Estados Unidos, en las que, sin incurrir en la exageración, se diluye el tan pregonado principio de igualdad jurídica entre los estados, o como menciona 
Marcelo Gullo: cuando están en juego los intereses vitales de las grandes potencias, el principio de la igualdad jurídica de los estados se transforma en una ficción que solo sirve a fines decorativos (Gullo, 2010, p. 27). Por lo tanto, en el contexto actual los procesos de integración en el marco del regionalismo abierto centran otras posibilidades de relación, propendiendo por una mayor separación y autodeterminación con respecto a la potencia del norte, esquemas posneoliberales.

Uno de los mecanismos para aumentar los márgenes de autonomía es la consolidación de esquemas de integración, sólidos y funcionales, que signifiquen espacios reales de construcción colectiva de objetivos comunes. No obstante, los procesos de integración latinoamericanos también dan cuenta de las dificultades de unificar las Relaciones Internacionales, si se compara con la Unión Europea: se cuenta con una variedad de acuerdos que, por lo menos como proceso, están distantes de llegar a la etapa a la cual han llegado los europeos.

\section{Referencias}

Álvarez, L. (2006). Historia del derecho internacional público. Bogotá: Pontificia Universidad Javeriana.

Báez, R. (2007). Monroísmo y Bolivarianismo confrontan en los andes. Tendencias, 8(1), 130-142.

Bolivar, S. (1978). Discurso de Angostura. Cuadernos de cultura latinoamericana (30). Briceño, J. (2014). Autonomía: genealogía y desarrollo de un concepto. Su relación con el regionalismo en America Latina. Cuadernos sobre Relaciones Internacionales, Regionalismo y desarrollo, 9-41.
Cardona, G. (2010). Comercio mundial: tendencias y estructura. Medellín: Esumer.

Cumbre Iberoamericana. (2014). 24Cumbre Iberoamericana. Recuperado de http:// www.24cumbreiberoamericana.gob.mx/ historia-de-la-conferencia/

Del Arenal, C. (2011). Del Arenal, CelestinoPolítica exterior de España y relaciones con América latina. Iberoamericanidad, Europeización y Atlantismo en la politica exterior española. Madrid: Siglo XXI.

Del Pozo, J. (2002). Historia de America Latina y del Caribe 1825-2001. Santiago de Chile: Lom.

Ffrench, R., \& Devlin, R. (1993). Diez años de crisis de la deuda latinoamericana. Comercio exterior, 5-20.

Gonzalez, C., Duarte, L., \& Montoya, D. (2014). Colombia de cara al nuevo regionalismo renovado: la alianza del Pacífico. Punto de Vista, V(9), 137-162.

Grisanti, L. (1999). Cumbre de la Unión Europea y de América Latina. Río de Janeiro. Guerra, A. (2008). Regionalismo y multilateralismo en su laberinto. Problemas del Desarrollo. Revista Latinoamericana de Economía, 11-28.

Guilherme, C., \& Lopez, A. (2009). Historia de Brasil; una interpretación. Salamanca: Universidad Salamanca.

Gullo, M. (2010). La insubordinación fundante: Breve historia de la construcción del poder de las naciones. Buenos Aires: Politeia. Halliday, F. (1994). Los finales de la guerra fría: una réplica. En R. Blackburn, El fracaso del comunismo y el futuro del socialismo (págs. 67-86). Mexico: Cambio XXI.

Jarque, C., Ortiz, M., \& Quenan, C. (2009). América latina y la diplomacia de cumbres. Mexico: Secretaría general iberoamericana. Lechini, G. (2014). La cooperación sur-sur en las politicas de Argentina y Brasil en el siglo $X X I$. Rosario: Unr Editora. 
Leiva, P. (2012). Estructura del acuerdo de asociación. En M. d. Chile, La asociación estrategica Chile-Unión Europea (págs. 4068). Santiago de Chile: Ministerio de Relaciones Exteriores Chile.

Lozano, Á. (2012). Stalin: el tirano rojo. Madrid: nowtilus.

Mingst, K. (2007). Fudamentos de las Relaciones Internacionales. Mexico: Cide.

Niño, J. (2008). Relaciones Internacionales de América Latina. Lectura para la configuración de un sentido comunitario eficiente. Revista de Relaciones Internacionales, Estrategia y Seguridad, 59-89.

Ocampo, J. A., Stallings, Bustillo, I., Velloso, H., \& Frenkel, R. (2014). La crisis latinoamericana de la deuda desde la perspectiva histórica. Santiago de Chile: Comisión Económica para América Latina y el Caribe.

Ocaña, J. (2003). Historia Siglo 20. Recuperado de Historia Siglo 20: http://www.historiasiglo20.org/GF/

Organización de Estados Americanos. (2013). Centro de Documentación del Derechos de los Derechos. Recuperado de Centro de Documentación de los Derechos: https://cd3. uniandes.edu.co/sistema_derechos_humanos/sistemas_principales/sistema_interamericano/documentos/tratados/carta_de_la_ organizacion_de_los_estados_americanos

Pérez, L. (2012). Elementos para una teoría de la politica exrterior. Valencia: Tirant lo blanch. Piñero, M. (2012). Recuperando la autonomía en la política exterior. En M. Bonetto, \& F. Martinez, Politica y desborde más allá de una democracia liberal (págs. 183-204). Villa Maria-Argentina: eduvim.
Puig, J. (1980). Doctrinas internacionales y autonomia latinoamericana. Caracas: Instituto de Altos estudios de América Latina. Real Academia Española. (02 de 10 de 2003). www.rae.es. Recuperado el $16 \mathrm{de}$ 06 de 2010, de http://buscon.rae.es/draeI /SrvltConsulta?TIPO_BUS=3\&LEMA $=$ proyecto

Rusell, R., \& Tokatlian, J. (2002). De la autonomía antagonia a la autonomía relacional: una mirada teórica desde el cono sur. Perfiles Latinoamericanos, 159-194.

Sanahuja, J. (2014). del «regionalismo abierto» al regionalismo post-liberal», crisis y cambio en la integración regional en América Latina. En l. Martínez, \& Lázaro, Anuario de la integración regional de América Latina y el Gran Caribe (págs. 11-54). Buenos Aires: Coordinadora regional de investigaciones económicas y sociales.

Tokatlian, J. G., \& Carvajal, L. (1995). Autonomía y política exterior: un debate abierto, un futuro incierto. Revista CIBOD d'Afers Internacionals, 3-31.

Torrado, V. (2005). La inmigración Latinoamericana en España. Mexico: Secretaría de Naciones Unidas.

Vera-Fluixá, R. (2000). Principios de integración regional en América Latina y su analisis comparativo con la Unión Europea. Bonn: Center for European integration studies.

Wollrad, D., Maihold, G., \& Mols, M. (2011). La agenda internacional de América Latina: entre nuevas y viejas alianzas. Buenos Aires: Nueva Sociedad. 